\title{
LOS ESTUDIOS SOBRE EL PODER LOCAL: PIANTEAMIENTOS Y TENDENCIAS SOBRE LA INVESTIGACIÓN RECIENTE *
}

\author{
por
}

\section{SANTIAGO DÍEZ CANO}

Universidad de Salamanca

RESUMEN: El artículo examina distintos trabajos relativos a un campo de investigación novedoso y que ofrece muchas posibilidades: el referido al estudio del poder local en la España contemporánea. Se agrupan las investigaciones más recientes en dos grandes lineas interpretativas, una más interesada en describir la funcionalidad de los poderes locales y otra atenta a la complejidad del mismo. Se analizan criticamente los resultados de esos estudios, poniendo de relieve sus pros y sus contras. Por último, se resumen algunas propuestas para avanzar en la investigación.

Palabras Clave: España. Edad contemporánea. Poder local.

ABSTRACT: The article examines different studies dedicated to an innovative research project on local power in contemporary Spain. The most recent research is grouped into two interpretive lines: one is more interested in describing the function of the local powers, and the other pays attention to the complexity of the latter. The results of these studies are analyzed critically, and the positive and negative aspects are underlined, in addition to sumarizing a few proposals for advancing the research.

KEY WORDS: Spain. Modern History. Local power.

La reflexión que sigue sobre los estudios y análisis acerca del poder local, pretende acercarse de una forma sumaria a un campo de investigación de importancia creciente en los últimos años y que constituye, dadas las características que posteriormente veremos, un especial punto de encuentro de propuestas revisionistas y nuevas en torno a distintos problemas. La reflexión quiere ser práctica y crítica. El punto de partida es una problemática concreta y a partir de ella, se exponen y abordan las cuestiones teóricas y/o metodológicas, intentando sugerir cuestiones para el debate, pero siempre desde una perspectiva enraizada en nuestros propios problemas.

Dicha problemática está contenida en un proyecto de investigación desarrollado desde hace unos años y que ha culminado su primera fase: acaban de ver la

* El presente articulo es una versión corregida de la ponencia presentada al Seminario sobre Poder local, celebrado en Valladolid los dias 10, 11 y 12 de febrero de 1997.

Hispanta, LIX/1, núm. 201 (1999) 97-111 
luz un Diccionario de parlamentarios de Castilla y Loón una serie de monografias tegional y provinciales sobre esta especial élite de poder (Carasa (dir.), 1997). En estos trabajos, no sólo hemos proporcionado nuevos datos sobre nuestros protagonistas, sino que hemos avanzado en una también nueva línea interpretativa acerca del periodo restaurador. Esta perspectiva supone una apuesta claramente revisionista a la hora de enfocar esta etapa, pues a nuestro modo de ver, hay que trascender la dicotomía interpretativa que todavía hoy nos envuelve, sobredeterminada por las visiones sesgadas hacia lo económico (Tuñón) o hacia lo político (Varela). En definitiva, necesitamos pasar «del bloque de poder al microanálisis" (Carasa y cols., 1996 a y b). Al analizar, mediante el método prosopográfico, la élite parlamentaria de la región en el período mencionado, nos dimos cuenta de que, si pretendíamos entender en toda su amplitud el poder de este grupo, si queríamos insertat - -como era nuestro propósito- su estudio dentro de una historia social del poder, debíamos investigarlo en relación con el espacio en el que se asienta y del que extrae su dominio. Ello nos llevaba, ineludiblemente, a enfrentarnos con la cuestión central del poder local y también a propiciar un tratamiento diferente del propio período restaurador.

De esta forma, nos situamos explicitamente en una posición claramente revisionista de esta etapa, tevisionismo que no quiere ni puede ser excluyente, sino todo lo contrario, en relación con las anteriores propuestas interpretativas. Como muestran los trabajos de raíz fundamentalmente local o regional aparecidos en los últimos años, parece cada vez más claro que es hora de superar las visiones clásicas de la Restauración y concebir la investigación edesde perspectivas más complejas, que tratan de insertar el más conocido funcionamiento del sistema político en la menos conocida realidad social, disponiéndose ya de suficientes materiales para evaluar y sistematizar interpretaciones de más ambición y alcances. (Forcadell, 1996).

Hemos delimitado con caracteres bastante definidos cómo era la élite parlamentaria de h tegión. Conocemos también parte de lo que significa su relación hacia arriba, con el poder central. Sin embargo, los datos de su comunicación hacia abajo aparecen más difusos. Esa telación descendente no parece posible aprehenderla desde los clásicos modelos interpretativos del periodo: ni acudiendo a la mera subordinación por motivos económicos, ni a través de la simple y elemental relación diádica característica del clientelismo. La existencia de un espacio fisico de análisis, determinado por cuestiones legales, como es el distrito, supone que contamos con un marco que debe ser investigado.

Este distrito uninominal, que domina casi sin interrupción la vida política española durante un amplísimo periodo de tiempo (de la etapa isabelina a la Dictadura de Primo, casi sin interrupción) hace que nos enfrentemos a la existencia de unas "400 Españas» (Romero, 1996) con características distintas y heterogéneas, subdivididas a su vez en un número muchísimo mayor de organismos locales, que son los referentes de primer orden en la vida de la mayor parte de la población.

Enfrentados, por tanto, al problema del poder local, necesitábamos algunos referentes a los que acudir para un enfoque adecuado de la investigación. En este sentido, hemos constatado, en primer lugar, el reciente auge de este campo de preocupaciones. Desde la politologia, la sociología, la antropología y la his-

Hispania, LIX/1, núr. 201 (1999) 97-111 
toria se está empezando a trabajar sobre lo que es y significa la vida local, que - como decíamos - supone uno de los primarios referentes de la experiencia vital de muchas personas a lo largo de la edad contemporánea.

Por razones expositivas, intentaré esquematizar algunas de las cuestiones que creo más nos pueden servir en nuestro concreto proyecto de investigación. Dejaré intencionadamente fuera las referencias a los trabajos realizados más allá de nuestras fronteras, por entender que tenemos aquí mejores especialistas para abordar dicha cuestion ${ }^{\text {. }}$.

Abiertos como estamos ya hace tiempo a una perspectiva interdisciplinar, nos preocupamos por comprobar si este tema específico de investigación contaba para disciplinas afines, como la Politología, Sociología o antropología políticas. Una inicial aproximación resultó algo decepcionante. Es verdad que los especialistas en ciencia política parecen preocupados por esta cuestión, pero parece que esa preocupación está enfocada sobre todo hacia la etapa más reciente de nuestra histotia (transición) y fundamentalmente a las cuestiones relativas a las élites locales (su origen, formación, las características de la misma en relación a la anterior élite franquista), así como por temas relativos a lo que los anglosajones llaman local government. Este sesgo, asi como la frecuente falta de sensibilidad histótica que catacteriza a buena parte de esta literatura, la hace poco útil para nuestros propósitos ${ }^{2}$ (Capo, Botella, López Nieto, Baras,...).

De mayor interés pueden resultamos algunos artículos relativos a cuestiones tales como el ordenamiento legal de los Ayuntamientos (Márquez Cruz, 1996), la importancia del clientelismo en la reciente antropología política (González Alcantud, 1996) o hs dimensiones micro y macro del clientelismo (Máiz, 1995 y 1996). Especialmente interesante me resulta el trabajo del profesor de la Universidad de Santiago, Ramón Máiz. Son artículos no referidos a la cuestión del problema local, sino a la reflexión teórica sobre el clientelismo, que se hace desde las teorías de la elección racional. Esquematizando mucho ese planteamiento, se pone de manifiesto en el mismo cómo el clientelismo resulta una opción muy attayente para los individuos concretos y que disuade de manera tremendamente efectiva a los mismos a participar en acciones colectivas caracterizadas por la agrupación hotizontal y la movilización en base a presupuestos ideológicos. De hecho, señala Máiz cómo este tipo de acciones colectivas (características de las sociedades más avanzadas, según opiniones ampliamente compartidas), tienen a menudo más que ver con h capacidad de los líderes de ofrecer incentivos selectivos a los participantes en las mismas que con su supuesta unión por motivos ideológicos (Maíz, 1996). Es posible que la verificación empírica de estos presupuestos teóricos resulte dificil, pero no estaría de más tenerla en cuenta a la hora de estudiar las concretas redes de apoyo establecidas bajo pautas clientelares.

1 Una inicial aproximación, sin embargo, puede efectuarse a través de los articulos de CruZ ARTACHO (1991) y Toscas (1991 y 1996). Véanse también las referencias concretas citadas en el artículo de TOSCAS que aparece en este volumen, así como el capítulo introductorio de su última obra (Toscas 1997b).

2 Al hilo de estas notas, sería bueno apuntar que resulta demasiado recurrente en los estudios politológicos o sociológicos esa falta de sensibilidad histórica.

Hipantia, LIX/1, núm. 201 (1999) 97-111 
Por parte de los historiadores, tenemos ya algunas pruebas recientes del creciente interés por estas cuestiones. Se han celebrado ya algunos congresos dedicados a esta temática, como los celebrados en Donostia en 1988 (Primeras Jornadas de Historia Local: poder local), el convocado por el Seminario de Historia Agraria en Cabezón de la Sal (1993), el II Congreso de Historia Local de Catalunya, dedicado monográicamente al tema del poder local, o el recientemente celebrado en Galicia sobre Caciquismo y poder local. Podemos decir también que hay ámbitos geográficos que han dedicado una mayor atención al tema: Cataluña, con el impulso fundamental de Jaume Suau y el grupo por él dirigido, del que han salido diversos trabajos e importantes reflexiones teóricas y metodológicas; el País Vasco, a través sobre todo de la labor del Laboratorio para el análisis del Antiguo Régimen; Andalucía, gracias a las investigaciones promovidas sobre todo desde Granada; Galicia o el País Valenciano son también zonas que han sido parcialmente estudiadas. Sin embargo, apenas estamos en los inicios, en el echar a andar de esta línea investigadora. Hace poco, recordaba Xavier Marcet que a pesar del reciente auge de estos estudios se estaba muy lejos de poder ofrecer una sintesis del tipo de la que ofrecía F.M.L. Thompson en su Historia Social de Gran Bretaña (Marcet, 1994).

A la luz de estos trabajos y teniendo siempre presente nuestro objetivo priotitario, podemos comentar algunas de estas iniciativas, contraponiendo lo que yo cteo que son dos grandes líneas interpretativas de lo que es y significa el poder local.

Una de ellas es la que se articula en torno a gran parte de los trabajos presentados al Seminario de Historia Agraria celebrado en Cabezón de la Sal, a las investigaciones promovidas y desarrolladas en el entorno andaluz y a algunas propuestas hechas desde Galicia. Hay también una excepción catalana, la representada por las investigaciones de Pere Salas.

La segunda tiene mucho que ver, en mi opinión, con la orientación dada por Suau a su grupo de investigadores; parte de Cataluña y allí encuentra su marco privilegiado de trabajo; es cierto también que esta forma de entender el local tiene muchos puntos concomitantes con lo que se hace en el País Vasco - la Comunidad Valenciana. Aquí tendríamos que mencionar los trabajos de Suau, Toscas, Marcet, Rubi, gran parte de los comunicantes del II Congrés d'Historia Local de Catalunya, algunos de los trabajos de Martí o lo hecho en el País Vasco por Martinez Rueda o Aguirreazkuenaga.

La primera de estas posiciones (primera en orden expositivo, no cronológico) se articula en torno a la cuestión de la funcionalidad de los poderes locales. Tal es el título con el que Manuel González de Molina sintetizaba la relación de comunicaciones que efectuó en el Seminario del S.E.H.A. (González De Molina, 1993). El autor, destacado exponente de una visión novedosa - con base ecológica- de determinados procesos históricos (sobre todo económicos), veía en el control del poder local, tanto en el Antiguo Régimen, pero sobre todo, tras la Revolución (cuando la unificación de poderes viene a sustituir a la anterior dispersión) el instrumento necesario para acceder al control del principal factor productivo, la tierra. Si tenemos en cuenta, como dice Molina, que la economía española del siglo XIX es sobre todo una economía orgánica (en la línea de lo expuesto por Wrigley), dicho control es el fundamento

Hispania, LIX/1, núm. 201 (1999) 97-111 
sine qua non para reproducir el capital. Las investigaciones realizadas en ámbitos tan diferentes como Andalucía (Cobo, Cruz Artacho, o el Grupo de Historia Social Agraria Andaluza) o también en Galicia (Cardesín, Fernández González) le servían para corroborar dicha impresión.

Esta propuesta, enmarcada en principio sobre todo en el periodo de tránsito del Antiguo Régimen al liberalismo, se traslada, casi sin cambios a periodos posteriores. De hecho, el caciquismo en el medio rural se explica de manera certera desde esta perspectiva. Creo que las recientes publicaciones de Cruz Artacho (Cruz Artacho, 1994 y 1996) pueden servir de resumen de esa posición, pues se basan no sólo en su propia investigación, sino en trabajos colectivos tealizados, como decíamos, desde Granada. Esa funcionalidad de los poderes locales entendida como instrumento necesario para controlar el factor tierra se extiende también al control de la mano de obra, una mano de obra a la que se quiere presta y disciplinada. Los efectos de la crisis agraria de fines de siglo y el aumento de la organización campesina estimulan la vía represiva adoptada por los poderosos locales andaluces.

Cruz Artacho estudia el caso granadino desde una perspectiva fuertemente enraizada en el tratamiento del poder local. Critica acertadamente la consideración del caciquismo como un sistema impuesto desde arriba y prefiere invertir la dirección de análisis; asimismo, plantea también con acierto que debe entenderse el fenómeno caciquil desde una perspectiva global, no reducible únicamente a fenómenos electorales, y privilegiando el marco rural que es donde mejor se advierten sus características; en este sentido, hace una utilización muy interesante de fuentes nuevas (judiciales especialmente), ofreciendo una interpretación novedosa, sugerente y bien articulada. Su reflexión teórica es muy crítica con lo que él considera equívocos planteamientos evolucionistas, procedentes de la teotía de la modernización, ineficaces a su entender para analizar marcos diferentes, rurales, que muestran características muy diversas a los centros urbanos, tradicionalmente privilegiados en el análisis del período. Le parece muy interesante la aplicación de conceptos traídos de realidades similares, como los de patronazgo o clientelismo, pero siempre analizados desde la perspectiva fundamental de la dominación, de la subordinación. Hasta aquí, no podemos sino manifestar amplios grados de coincidencia. Las discrepancias vienen motivadas por el elemento explicativo que se introduce entonces y que no sólo impregna sino que determina todo el trabajo: la organización del caciquismo en la provincia granadina no sería sino un instrumento de las clases dominantes (la oligarquía agraria) para imponerse a la clase subordinada; con sus propias palabras:

"el fenómeno del caciquismo, los actos de fraude, etc., no serán vistos como una mera expresión del grado de instrucción del cuerpo electoral, sino como una forma concreta de articular la lucha que se establece entre las estrategias de poder de las clases dominantes en el mundo rural y los mecanismos de resistencia a las mismas que ofrecen el resto de la comunidad, formada en su gran mayoría por campesinos pobres y jornaleros agrícolas. El caciquismo no se convierte, pues, en una «lacra ansiada y necesaria» (colchón amortiguador de tensiones sociales) con el fin de lograr la "modernización política» de la sociedad, sino que más bien es expresión de la lucha de clases en el campo. En 
este sentido, la modificación de la atticulación del conflicto rural se traducirá inmediatamente en un cambio en los comportamientos políticos. En suma, en palabras de Antonio Ramos Oliveira, las actuaciones caciquiles no son producto de una lucha entre letrados e iletrados, sino expresión de una desigual e injusta distribución y control del factor tierras (Cruz Artacho, S. 1994, 47).

Aunque centrado en el caso granadino, la propuesta tiene -creo- una clara ambición de ser extrapolada a situaciones vividas en otros ámbitos. De hecho, como hemos comentado, la interpretación que hacía González de Molina relacionaba el ámbito andaluz con otros, como el gallego o incluso el riojano. Pere Sala, desde sus investigaciones centradas en el ámbito rural mallorquín, propone algo parecido. En definitiva, el poder local aparece sobredeterminado por el poder económico, prácticamente reducido al mismo.

En su contribución al trabajo colectivo sobre clientelismo en España, Cruz Artacho insiste en sus proposiciones, interpretando las relaciones clientelares en el ámbito andaluz como relaciones de dominación, basadas en el desigual acceso al factor productivo tierra (Cruz Artacho, 1996). La misma posición se advierte en las contribuciones tecogidas en este mismo número, expuestas en un Seminario celebrado en Valladolid en 1997, con la salvedad de que a través del artículo de Cobo, podemos ver cómo el ámbito cronológico se extiende hasta el final de la guerra civil y el primer franquismo.

Para nuestros propósitos, esto es útil, pero insuficiente. No parece que podamos entender todo el proceso de relaciones caciquiles desde esa perspectiva fundamentalmente económica, aunque no debamos perderla de vista. Además, desde el mismo ámbito andaluz, hay formas diferentes de entender las cosas. Recientemente, se ha publicado la tesis doctoral de María Sierra (Sierra, 1996), que tiene, como bien sabemos, una visión distinta de lo que significa el clientelismo en la región andaluza. Es cierto que sus opciones teóricas son diferentes, que reduce sus conclusiones a los ámbitos urbanos o a las agrociudades y deja abierta, para el entorno rural la posibilidad de que el caciquismo se explique simplemente por cuestiones de pura y dura subordinación. Es cierto también que María Sierra se sitúa en una posición un tanto ecléctica en lo concerniente al debate actual sobte el significado de la Restauración, peto no lo es menos que se advierte en su trabajo un sesgo hacia una interpretación que privilegia los aspectos consensuales del sistema y orilla los que nos conducen a una visión conflictual del mismo.

En definitiva, y puesto que ambos tipos de investigación tienen -con razones para ello- pretensiones de explicar los fundamentos del sistema y no quedarse en el ámbito local que analizan, tenemos dos visiones casi excluyentes de lo que es el poder y sus fundamentos en Andalucía. No sé si habría maneras de tender puentes entre ambas, ni siquiera sé si ello sería plausible, pero sí creo que debe advertirse del peligro implícito en ambas visiones, que es el de una cierta marginación de las capas subordinadas.

María Sierra utiliza el concepto de clientelismo en el sentido de relaciones individuales y diádicas entre personas de desigual condición, que a través de ese pacto personal se obligan mutuamente. Puesto que el grupo social que sustenta 
básicamente esta relación clientelar es el perteneciente a las clases medias, parecería que las capas populares serían en gtan medida un mero objeto manipulable o intercambiable por parte de los patronos o de los clientes de esos patronos. María Sierra entiende además que el sistema clientelar deja escasos rastros en el ámbito rural, por lo que privilegia en su análisis el ámbito urbano o semi-urbano y también las relaciones entre los primates provinciales y las clientelas en esos ámbitos. No se desciende a analizar en profundidad las relaciones mantenidas en el ámbito local entre los clientes de los patronos provinciales y las distintas comunidades (más allá de las genéricas referencias a la dispensa de favores colectivos).

Sucede, sin embargo, que también en la visión proporcionada por el grupo granadino, se puede deslizar el investigador hacia un plano excesivamente predeterminado. No es que aqui falten las acciones, opiniones y actuaciones de las capas subordinadas, más bien al contrario, pero dado el escenario en que éstas se producen, nos situamos ante un panotama prácticamente cerrado: el control del poder por parte de una oligarquía parece abrumador y omnímodo, y la respuesta de las capas subordinadas está, cuando se produce, estructuralmente determinada por características violentas, a las que se responde sistemáticamente con altos niveles de represión. Cuando no se da esto, simplemente hay resignación (o poco más). Las preguntas a plantearse serían las de si el poder local gira única y exclusivamente en torno a la cuestión de la tietra, si no se advierten problemas en el seno de ese homogéneo bloque dominante y si únicamente la represión o un sistema de dominación disfrazado de pattonazgo son las exclusivas relaciones entre el poder y los dominados. Así como en la visión anterior se privilegian las relaciones consensuales, aquí lo hacen las referidas al conflicto. Me parece - con Forcadell - que conflicto y consenso pueden coexistir sin más problemas. Además, aunque no nos centremos en demasía en esa visión, no debemos olvidar que estamos ante actores individuales que analizan las distintas posiciones que pueden adoptat.

En cualquier caso, esos esquemas no nos parecen suficientes para analizar la realidad que tenemos entre manos. Ni por mecanismos exclusivamente pactistas o exclusivamente de dominación se explican las relaciones entre el poder o poderes locales y las distintas comunidades en nuestra región.

Hay otra manera de entender el poder local, que no gira en torno al control de la tierra, sino en una concepción más poliédrica de lo que sería el poder local. Para valorarla, podemos partir de la breve pero enjundiosa propuesta de Jaume Suau (Suau, 1991 y 1992). Recordemos algunos de sus rasgos básicos: las colectividades no son «unidades sociales homogéneas y armónicas», sino que en ellas los recursos y el poder se distribuyen de forma asimétrica. Ello no significa -empero- - que haya una única instancia de poder, sino varias, distintas facciones con poder. Éste sería un "fenómeno esencialmente social y políticon, no independiente de lo económico, pero sí autónomo. Autónoma es también la esfera local como unidad de análisis; es en esa esfera donde pueden verse a menudo con más claridad que a nivel global, las relaciones de poder. Lo local, entonces, no es un mero apéndice del Estado y es mejor analizar su in-

Hispanta, LIX/1, núm 201 (1999) 97-111 
serción en la política estatal a través de las distintas redes de integración y también de las relaciones de fuerza entre ambas instancias que ello comporta. Por otra parte, el poder ha de entenderse en un sentido dinámico, como inductor de la reproducción de relaciones sociales o también de su cambio. Una cuestión que no está explícita en el planteamiento de Suau, pero que se deduce de ella y es prontamente utilizada es que en esas relaciones entre Estado y colectividades locales, debemos tener en cuenta el carácter de esas relaciones en el marco concreto español, no sólo para entender la cuestión del poder local en Cataluña (Rubi, 1992), sino en otras zonas (por ejemplo, el País Vasco, Aguieazkuenaga y Martínez Rueda, 1995).

Esta opción apuesta por la complejidad y quizás debido a ello, muestra bastantes imágenes en negativo, es decir, abunda en lo que no debería ser el estudio del poder local. Quizás lo entendamos mejor con una cita de uno de los integrantes del equipo de Suau (Marcet, 1994 y 1995).

Es importante no confundir poder local con instituciones políticas. Por ello es conveniente hablar de poderes locales y estudiar su local combinación, agregando los poderes económicos y sociales a los elementos políticos. El factor clave a mi entender está en descubrir esa combinación, a veces disfrazada de suplantación. Es útil pero insuficiente afrontar la cuestión del poder local desde la perspectiva estrictamente legal. Es útil pero insuficiente tener un buen conocimiento de la distribución de la propiedad y de los principales agentes económicos, con las relaciones familiares que se acostumbran a dibujar o con las instituciones que se suelen constituir si no logramos establecer los canales por los que estos intereses económicos se plasman en el espacio local, a través de políticas, de presencias, de grupos. Es útil pero insuficiente estudiar las dinámicas locales de los partidos estatales o nacionales - muchas veces sustituidos de facto por asociaciones que recogen la particulatidad de la localidad- si no logramos establecer aquellos intereses o grupos que presionan para obtener determinadas decisiones o para controlar las relaciones del poder local con otros jerárquicamente superiores. Todos estos factores son útiles y son factores decisivos, pero el estudio del poder local debe responder a una combinación de todos ellos, junto con un conocimiento profundo de la comunidad donde operan, y junto a un especial análisis de las relaciones de los poderes locales con otras esferas del Estado. Es en la relación de estos factores donde podemos establecer los mecanismos que estructuran el poder local, más allá de la formalidad de sus cargos, y también más allá de presuntas correlaciones mecánicas entre poder económico y poder político. El poder local es una geografia de proximidades, donde los factores personales adquieren algunas veces cotas de gran importancia, con odios y sectarismos de gran viscetalidad. Establecer este panotama de cercanías personales y políticas es fundamental para entender quien manda en una ciudad.).

Después de esto, Marcet hace referencia a la escala de la ciudad y al factor continuidad, que él estima importante, por ir unido a un discurso fuertemente localista, un ismo que entiende el marco local como el centro fundamental de intereses y lo presenta como un todo que debe armonizar los distintos cuerpos

Hispania, LIX/1, núrr. 201 (1999) 97-1t1 
que lo componens. De hecho el factor continuidad es analizado en la ponencia conjunta y tripartita de Marcet, Canales y Rubí presentada al II Congreso Internacional de Historia Local de Catalunya, y que analizaba los casos de Tarrasa, Sabadell, Vilanova y Manresa. Reseñada la importancia del continuismo, también se acepta la desmitificación del mismo.

Dentro de este proyecto investigador, contamos con una de las aportaciones más densas, estructuradas y abarcadoras. Nos referimos a las investigaciones de Eliseu Toscas, quien ha aportado más ideas a las ya mencionadas, sobre las que ha seguido insistiendo en sus balances sobre la historiogtafia francesa o su crítica y aportaciones a un congreso celebrado en Francia sobre Poder local y revolución (Toscas, 1991, 1993, 1995a). Pero además, ha aportado nuevas perspectivas: la importancia de las redes personales (1995b), o la importancia de la interrelación campo-ciudad (1996). Su tesis doctoral (Toscas, 1997) tesume y compendia un dilatado esfuerzo investigador y se constituye en referencia ineludible en los estudios sobre poder local. Ahí encontramos la -a mi juicio-mejor decantación de todo este enfoque.

En definitiva, el espectro interpretativo se ha ampliado aún más, incorpotando nuevas perspectivas, que a su vez abren dicho campo.

En esa misma línea se mueven otros trabajos, como la relación efectuada por Millán en el Congreso del SEHA o en el de Santiago (Millán, 1993, 1996) o los de Martí (Martí, 1995a, 1995b). Millán, por ejemplo, hacia, sobre los mismos materiales, una lectura diferente a la propuesta por González de Molina.

Enfatiza también la validez del estudio local, válido para desmontar tópicos demasiado corrientes en la historiografia española, así como la evolución diferente del mundo rural; insiste, igual que otros autores, en los límites de la acción del Estado y, por tanto, recuerda (con Suau) la notable esfera de autonomía que tiene el espacio local. Sin embargo, en relación con el sujeto y las fuentes del poder, mantiene una posición más abierta, menos unilateral. Y, por último, matiza el carácter de la relación entre los poderosos y los dominados, señalando que junto al conflicto, hay que hablar de relaciones de consenso. Recordemos que estamos hablando de dos resúmenes efectuados sobre las mismas comunicaciones; como podemos ver, las lecturas tienen perspectivas divergentes. Millán efectúa nuevas derivaciones y complejiza aún más la problemática en su ponencia presentada al Congreso celebrado en Galicia (Millán, 1996). Como afirma en sus conclusiones, el estudio de los podetes locales no debe servir sólo para rescatar aspectos normalmente marginados, sino, sobre todo ipara integrar campos de conocimiento diferentes y plantear problemas novedosos para la investigación. El análisis a corta distancia de las relaciones entre la política, los grupos de poder y el cambio social constituye un campo insustituible para ellow ${ }^{3}$.

3 La ponencia ("Campesinado y cambio social en la politización de la sociedad contemporánea. Una discusión sobre el conservadurismo agrario valenciano») parte de la reflexión de los orígenes de la unueva» derecha valenciana de los años 30 , relacionada con el carlismo y el sindicalismo agrario valenciano. De ahí deriva a analizar los complejos modos de la politización de los 
Manuel Martí se mueve en esa misma línea. Quizás uno de los mejores ejemplos, sería su comunicación al Congreso sobre poder local celebrado en Barcelona y titulada significativamente «Elogio de la discontinuidad». Elpoder politico local entre los siglos XIX y XX (Martí, 1995a). En ese trabajo, Martí se dedica a poner en cuestión algunos de los tópicos -incluso recientes- relativos al análisis de la vida política local en el marco alicantino: el dominio incontestado por parte de un poder local casi perpetuo, la desmovilización política, la supuesta identidad básica de las opciones políticas del turno, etc. Martí propone hipótesis diferentes, centradas en reconstruir la concreta dinámica de la vida política local y en un "análisis comparado sobre investigaciones de ámbito territorial testringido, bien documentado, de larga duración y orientado a un análisis social de los fenómenos políticos». En su contribución al presente número (que tecoge asimismo una exposición en el Seminario anteriormente citado) nos ofrece - además- una inserción de estos estudios dentro de una perspectiva más global, que revela la potencialidad heurística de estos trabajos.

Confieso que me siento bastante identificado con la propuesta crítica y las múltiples sugerencias derivadas de este modo de enfocar el poder local. Sin embargo, más allá de las declaraciones de intenciones y a la espera de propuestas normativas dotadas de una mayor articulación, he de decir también que uno se siente sugerentemente atraído y desorientado. Lo que se deduce de esto es más lo que no hay que hacer que lo que debemos investigar $y$, sobre todo, cómo articularlo. De hecho, la articulación se refiere a cuestiones parciales y a propuestas todavía muy centradas en las élites de poder y más concretamente en las élites que ocupan los cargos en las instituciones, prioritariamente los Ayuntamientos. A fuerza de querer evitar los peligros de interpretaciones homogéneas (básicamente el reduccionismo), creo que existe otro peligro posmoderno: hay mucho de deconstrucción, y poco de articulación. Es como si el inicial esquema de Suau, enseguida se hubiera extendido y desviado, enlazando rápidamente con otras múltiples esferas. Creo que esto debe ser objeto también de discusión: ¿cómo evitamos, si es que hay que hacerlo, el peligro de dispersión de este enfoque interpretativo? Un buen esquema es el que nos

campesinos y la relación de esto con los poderes locales. Millán critica el supuesto aislamiento de los poderes locales en relación con la politica estatal y el supuesto predominio de las relaciones clasistas o de dominación y patronazgo en el mundo rural. Asimismo, entiende que una visión en exceso comunitaria de lo que es la vida campesina contribuye a ocultar las formas concretas en que se vive la política y las relaciones sociales en las áreas rurales (con mecanismos de relación, integración y consenso también). Frente a la visión de un mundo rutal arcaico, anclado en valores semifeudales, hay que entender la concreta dinámica de las microsociedades. Así, se entenderían mejor aspectos como la movilización puntual (analizada hasta ahora como algo meramente explosivo, coyuntural) o el éxito de formulaciones - realizadas por ciertas élites- que saben integrar viejas aspiraciones de tipo comunitario con fenómenos de política moderna. Ello enlazaría con fenómenos analizados en el marco catalán, como el salisme, o castellano (kantes que el cunero, de casa el cabreron, como decían en algún pueblo soriano).

Hippania, LIX/1, nüm. 201 (1999) 97-111 
propone Toscas (Toscas, 1997a y su artículo en este mismo número), aunque yo me permitiria añadir alguna cosa más.

En este sentido, estimo que hay --sobre todo- una laguna amplia que necesita ser llenada: la referida a las relaciones entre los poderes locales y las capas dominadas, subalternas, objeto del poder o como se quiera. A la trilogía de Suau, qui mana, cóm, per quê?, podríamos añadirle sobre quién... Quizás por cuestiones de método o de tiempo, me parece que están todavía este tipo de estudios centrados en la primera parte de esa pregunta: ¿quién manda? Es perentorio adentrarse en sobre quién.

Llegados a este punto, hay que advertir que incluso nosotros, que apenas hemos empezado a profundizar en el tema del poder local, estamos en una situación parecida a esta última que acabo de comentar. Ya he mencionado en qué estado se encuentra nuestro proyecto. A ello se añaden las reflexiones que desde hace años ha aportado Carmelo Romero (Romero, 1989a, 1989b, 1996a, 1996b) y que han puesto el dedo en la llaga a la hora de desmontar tópicos en cuanto a la actitud supuestamente apolítica y pasiva de las comunidades rurales castellanas. Su última relación, aunque muy centrada en la cuestión electoral, resalta el hecho de la importancia de los espacios políticos que son los distritos electorales, permanentes, como hemos dicho, a lo largo de un amplio período de tiempo. Nuestro análisis de la élite parlamentaria de la Restauración también se mueve en esos parámetros. El problema estriba entonces en cómo conectar los distintos planos. A fin de cuentas, seguimos sin saber, como decía Álvarez Junco (Álvarez Junco, 1996) recientemente, qué pasaba realmente en los pueblos españoles en 1900, por ejemplo cómo se vivían en ellos los cambios políticos, los grandes acontecimientos. Su propuesta va en la línea de introducir un enfoque de cultura política y de paso de una cultura política localista (parroquial o de súbdito) a otra nacional o participativa. Las élites, los poderes locales serían protagonistas primordiales de ese proceso. El problema es que el planteamiento de Alvarez Junco sigue afectado de una visión en exceso evolutiva de lo que es la vida política española.

A riesgo de aumentar el grado de complejidad que tiene el tema de la investigación del poder local, voy a introducir dos elementos no diré que nuevos, porque ya han aparecido, pero sí enfocados desde otra perspectiva: la cuestión de las redes y la del consenso.

La primera me parece primordial para entender los aspectos relacionales de la cuestión. Por mucha autonomía que advirtamos en su configuración, todos estamos de acuerdo en que ese poder local lo es también en tanto en cuanto es capaz de relacionatse con otros poderes de ámbito superior o de mantener distintos tipos de relaciones en su interior. Hay que potenciar el análisis de este complejo mundo de relaciones. Los modernistas lo saben bien y han sacado amplio provecho de este enfoque investigador. Una buena reflexión sobre sus virtudes y problemas podemos encontrarlos en la información proporcionada por José María Imizcoz (Imizcoz, 1996). Juan Pro ha tecordado también la utilidad de este tipo de análisis (Pro, 1995). 
La otra cuestión tiene que ver con una de las fallas que yo advierto en los estudios sobre poder local, que creo que es explicable, pero debe ser corregida: nos hemos fijado mucho en quién manda y menos en las relaciones sobre los mandados. Es verdad que este aspecto está más tratado en la perspectiva granadina (por así decir), pero ya he mostrado mis discrepancias en cuanto a ella. También que por parte de los estudiosos catalanes o levantinos se nos ha avisado de la capacidad de las élites para configurat y reproducir espacios de poder que de alguna forma implican a todo un colectivo (recordemos el salismo en Terrasa, el conservadurismo valenciano, etc), pero creo que hay que ir más allá.

G. F. de los Arcos nos ha proporcionado hace poco una reflexión interesante -aunque algo desarticulada- de cómo debería enfocarse el estudio del poder. Según ella, se trata de un proceso que se opera entre dos, los dominantes y los dominados; por tanto, habría que poner en relación el estudio del poder con las masas, no porque - como afirma la autora- ello no se haya hecho nunca, sino porque se trata de una línea que hay que perfeccionar. Como en todo proceso entre dos partes, no hay aquí una sola dirección -la que tradicionalmente se privilegia-, de los dominantes a los dominados, sino líneas de influencia que se cruzan e influyen mutuamente. Su propuesta, de notorio interés para nosotros, plantea un estudio del poder «a ras de suelo», en sus aspectos más cotidianos y, por lo tanto, más reales y efectivos. Incluso, avanza una propuesta metodológica: analizar los grupos de poder, los espacios en los que se ejerce o prepara ese ejercicio del poder y las personas que intervienen en él. (G. de los Arcos, M. F., 1993).

En relación con esto, está la última propuesta, la relativa al consenso. Hemos advertido que este tema está presente en las investigaciones sobre la cuestión de los poderes locales, y sé que puede suscitar amplias dosis de techazo. Pero creo que no podemos eludirla. No parece que el sistema de la Restauración tuvieta tan larga vida simplemente utilizando para pervivir mecanismos exclusivamente de represión o de clientel a. Hemos ido viendo cómo las élites eran capaces de generar adhesiones más allá de un sistema estrictamente clientelar, es decir, generaban consenso.

Quizás podamos aprender algo de algunos colegas dedicados a otra etapa, el franquismo. Una excelente tesis de Cándida Calvo abordaba explícitamente esta cuestión para el caso guipuzcoano. Una parte, la dedicada a la discusión conceptual, ha sido publicada recientemente (Calvo, 1995). En ella, encontramos sugerentes reflexiones sobre la utilidad del concepto, aunque lógicamente, hay que tener en cuenta el ámbito específico al que se dirige la investigación: un tégimen dictatorial. Aun asi, las explicaciones que ofrece $h$ autora acerca de la persistencia del concepto, de su genealogía, de los mecanismos para estudiarlo, de las fórmulas empleadas por los regímenes dictatoriales para suscitar consenso, puede que nos sean de utilidad si somos capaces de adecuar su investigación a otro tipo de tegímenes politicos y de circunstancias históricas.

En resumen, tenemos mimbres para hacer cestos, pero la discusión queda abierta en torno a los diseños de modelo teórico-metodológico en el cual encuadrar la investigación.

Hispania, LIX/1, núm. 201 (1999) 97-111 


\section{BIBLIOGRAFIA}

Actas do Congreso Internacional Poder local, elites e cambio social na Galicia non urbana (1874-1936), Santiago de Compostela, 14-15 xuño 1996, Santiago de Compostela, Universidade, 1997.

Actes del II Congres Internacional d'Història Local de Catalunya. Formes i relacions del poder local a l'època contemporània, Barcelona, L'Avenç, 1995.

AGUIRREAZKUENAGA, J.; MARTINEZ RUEDA, F. (1995); «Reflexiones y propuestas desde Euskal Herria-Vasconia sobre el analisis de los poderes locales y su investigacióny, en Actes del II Congrès, ....it.

ÁLVAREZ JUNCO, J. (1996); «Redes locales, lealtades tradicionales y nuevas identidades colectivas en la España del siglo XIX,, en ROBLES EGEA, A. (ed.): Politica en penumbra. Patronazgo $y$ ckientelismo pokticios en la España contemporánea, Madrid, Siglo XXI, pp. 21-42.

AYALA, F.; TOSCAS, E.: «Estat i vida politica local: Sarrià i Masquefa a mitjan segle XIX», en L'Avenf, n'. 160, 1992.

BALMAND, P. (1992): «La renovación de la historia política», en BOUDRE, G., MARTIN, H.: Las escuelas bistóricas, Madrid, Akal, pp. 251-268.

BARAS, M. (1992): «Elites municipales y partidos políticos: 1983», en Revista de Estudios Politicos, $\mathrm{n}^{\circ} .76$, abril-junio, pp. 161-177.

BIAREZ, S. (1989): Le pouvoir local, Paris, Economica.

BO'IELLA, J. (1992): «La galaxia local en el sistema político españols, en Revista de Estudias Politicos, $\mathrm{n}^{\circ} .76$, abril-junio, pp. 145-159.

CALVO VICENTE, C. (1995): «El concepto de consenso y su aplicación al estudio del régimen franquistas, en Spagna contemporanea, $\mathrm{n}^{\circ} 7$.

CAPO, J. y otros (1988): «La formación de una élite politica local», en Revista de Estudios Politicos, $\mathrm{n}^{\circ}$. 59, enero-marzo, pp. 199-224.

CAPO, J. (1992): «La élite política local en España», en Revista de Estudios Politicos, $\mathrm{n}^{\circ}$. 76, abril-junio, pp. 127-143.

CARASA, P. (dir.) (1997): Élites castellanas de ka Restauración, Salarnanca, Junta de Castilla y León, 2 vols.

- (1996): «Élites castellanas de la Restauración. Del bloque de poder al microanálisisn, en Historia Contemponánea, $\mathrm{n}^{\circ}$. 13-14, pp. 157-196.

- (1996): «Poder político, poder económico y parlamentarismo en Castilla durante la Restauracióny, en Revista de Estudios Políticos, $n^{\circ} .93$, pp. $139-176$

- (1994): Élites. Prosopografia contemporánea, Valladolid, Universidad de Valladolid, 1994

-.: «La recuperación de la historia política y la prosopografia», en CARASA, P. (ed.): Élites,... cit., Pp. 41-52.

- (et alii) (1990): «Castilla en las Cortes de la Restauración. Poder político y dominio social de la oligarquía vallisoletana, 1876-1903"), en Las Cortes de Castilla y León, 1188-1988, Valladolid, Cortes, 1990 , vol. II, pp. 457-477.

COLOMINES, A.; OLMOS, V. S. (1991): «L'espai local: una proposta de recerca històrica», en L'Aveng, Abril.

CRUZ ARTACHO, S. (1991): «Clientelismo, patronazgo y estrategias de poder en la sociedad rural italiana contemporánea. Una primera aproximación bibliográficas, en Noticiario de Historia Agraria, n०. 2, 1991, pp. 123-127.

- (1994): Caciques y campesinos. Poder politico, modernización agraria y conflictividad rural en Granada, 1890-1923, Madrid, Ediciones Libertarias.

- (1996): «Estructura y conflicto social en el caciquismo clásico. Caciques y campesinos en el mundo rutal granadino (1890-1923)», en ROBLES EGEA, A. (ed.): Politica en penumbra. Patronazgo y clientelismo politicas en la España contemporánea, Madrid, Siglo XXI, $\mathrm{pp} .191-213$.

Espacio, Tiempo y Forma. Serie $V$. Histona Contemporánea, 3/1 y 6 (monográficos dedicados a las élites), Madrid, UNED, 1990 y 1993.

FORCADELL, C. (1996): «De la Revolución democrática a la Restauración: el horizonte de una historia socialy, en La Historia Contemporánea en España, Salamanca, Universidad, pp. 103123. 
Forner, S., GarCia, M. (1990): Cuneros y caciques, Alicante, Patronato Municipal del V Centenatio.

FERNÁNDEZ GONZÁLEZ, A. (1995):: «Los grupos de poder local en Galicia, 1750-1850», en Noticiario de Historia Agraria, no. 9, pp. 129-153.

G. DE LOS ARCOS, M². F. (1993): «El ámbito de la nueva historia política: una propuesta de globalizacióny, en Historia Contemporánea, n'. 9, pp. 37-57.

GONZÁLEZ DE MOLJNA, M. (1993): «La funcionalidad de los poderes locales en una economía orgánicas, en Noticiario de Historia Agraria, n ${ }^{\circ}$ 6, pp. 9-23. Historia Contemporánea, n': 8: Las élites en la España Contemporánea, Bilbao, Universidad del País Vasco, 1992. Historia Contemporánea, $\mathrm{n}^{\circ}$. 9: La nueva historia política, Bilbao, Universidad del País Vasco, 1993.

IMIZCOZ BEUNZA, J. M. (1996):: «Comunidad, red social y élites. Un análisis de la vertebración social en el Antiguo Régimens, en IMIZCOZ, J. M. (dir.): Elites, poder y red social. Las élites del País Vasco y Navarra en la Edad Moderna, Bilbao, UPV, pp. 13-50.

LOPEZ NIETO, L;; DELGADO, I. (1994): «Innovación urbana española: zuna nueva clase política3), en Reyista de Estudios Politicos, $\mathrm{n}^{\circ}$. 86, MANN, M. (1991): Las fuentes del poder social I., Madrid, Alianza.

MÁRQUEZ CRUZ, G. (1992): «Las élites políticas locales de izquierdas en Andalucía: de la transición local a la normalización institucionabn, en Revista Internacional de Sociologia. Tercera época, $n^{\circ} .3$, pp. 143-181.

- (1996): «El sistema político local desde las Cortes de Cádiz a la Restauración (1810-1923): cuestiones metodológicas", ponencia presentada al Congreso Poder Local, Élites e cambio social na Galicia non-urbana, Santiago de Compostela; recogida en Actas do Congresa... cit, pp. $29-140$.

MARTí, M. (1995): «Elogi de la discontinuitat. El poder politico local entre els segles XIX y $\mathrm{XX}$, en Actes, cit.

MARTÍNEZ RUEDA, F. (1994): Los poderes locales en Viqcaya. Del Antiguo Régimen a la Revolución Li. beral, 1700-1853, Bilbao, Universidad del País Vasco, 1994.

MAÍZ, R. (1995): «Estructura y acción: elementos para un modelo de análisis micropolítico del clientelismon, en Revista Internacional de Sociologia, $\mathrm{n}^{\circ} .8-9$, pp. 189-215.

- (1996): «Estrategia e institución: el análisis de las dimensiones macro del clientelismo politicon, en ROBLES EGEA, A. (ed.): Politica en penumbra. Patronargo y clientelismo politicos en la España contemporántea, Madrid, Siglo XXI, pp. 43-67

MARCET, X. (1994): (Los mecanismos de poder local en Catalunya», en AGUIRREAZKUENAGA, J.; URQUTJO, M. (eds.): Perspectivas de la bistoria local en Catakña, Bilbao, Universidad del País Vasco, pp. 105-116.

- (1995): «Formes i mecanismes de continuiitat del poder en l'espai local. In, en Actes del II Congrìs..., it.

MILLAN, J. (1993): «Poderes locales, conflictividad y cambio social en la España agraria. Del Antiguo Régimen a la sociedad burguesas, en Noticiario de Historia Agraria, $n^{\circ}$. 6 , pp. 25-36.

- (1996): «Campesinado y cambio social en la polización de la sociedad contemporánea. Una discusión sobre el conservadurismo agtario valencianon, ponencia presentada al Congreso Poder Local, Elites e cambio social na Galicia non-urbana, Santiago de Compostela, recogida en Actas do Congreso..., cit. pp. 161-188.

PRo RUIZ, J. (1993): «Las élites locales y el poder fiscal del Estado en la España contempotánean, en Les élites locales et l'état dans lEspagne moderne (du XVI au XIX siècle), Paris, CNRS, pp. 283-294.

- (1995): «Las élites de la España liberal: clases y redes en la definición del espacio social (1808-1931)m, en Historia Social, $\mathrm{n}^{\circ}$. 21, pp. 47-69.

REMOND, R.: Pour the histoire politigue, Paris, Seuil, 1988.

ROMERO, C. (1989a): «La suplantación campesina de la ortodoxia electoral), en Jornadas sobre Caciquismo y electiones. Realidades politicas en la Castilla de la Restauración, Medina del Campo (inédito).

Hi.ipunia, LIX/1, núm. 201 (1999) 97-111 
- (1989b): «Notas sobre las características socioeconómicas y las actitudes políticas del campesinado castellano durante la segunda mitad del siglo XIX y el primer tercio del siglo XX", en Haciendo Historia. Homenaje al profesor Carlos Seco, Madrid, Universidad Complutense.

- (1996a): «Tensión y conflicto en la España interior durante la Restauración», en VIII Curso Universitario de verano. Universidad de Santa Catalina, Soria, Ayuntamiento del Burgo de Osma.

- (1996b): «Estado débil, oligarquias fuertes, o "Las palabras para el gobernador, los votos pam el obispo" ", ponencia presentada al Congreso Poder Local, Elites e cambio social na Galicia non-urbana, Santiago de Compostela, recogida en Actas do Congresa..., cit., pp. 141-159.

RUBI, M. G.: «El poder local en una ciutat industrial a la Catalunya de la Restauración, en L'Avenç, $\mathrm{n}^{\circ} .160,1992$

SIERRA, M. (1996): La politica del pacto. El sistema de la Restauración a través del partido conservador sevillano, Sevilla, Diputación Provincial.

SOLA, A.: Poder político y grupos de poder, en CARASA, P. (ed.): Élites,... cit., pp. 25-34.

SUAU, J. (1991): «Metodología y fuentes para el estudio de las élites en España (1834-1936)", en Noticiario de Historia Agraria, $\mathrm{n}^{\circ} .2,1991$, pp. 211-216.

- (1992) "Qui mana? Com? Per què? Estudi de les relacions de poder en les col-lectivitats ruralsw, en L'Aven;, ñ. ${ }^{\circ} .160,1992$.

TOSCAS, E. (1991): «Los estudios sobre el poder local en la Francia rural (ss. XVIII-XIX). Un comentario bibliográficon, en Noticiario de Historia Agraria, n². 2, pp. 113-122.

- (1992) «obre la qüestió política local a mitjan segle XIX. Aproximació a l'estudi de les relacions entre els poders locals i l'ajuntament al municipi de Sarrià en 1840-1856\%, en Estudis d'Historia Agraria, n'. 9, 1992, pp. 73-126.

- (1993a) «Elements de continuitat política local a la Barcelona del primer terç del segle XIX, en $A f e r s, n^{\circ} .15$, pp. 162-174.

- (1993b) «Poder local y revolución, 1780-1850: balance crítico de un coloqui internacionab), en Noticiario de Historia Agraria, n'. 6, pp.

- (1994) «Poderes locales y Estado en la Catalunya del s. XIX. Una investigación en curso», en Bullettino del diciannovesimo secolo, 3, pp. 60-62.

- (1995a): «Les rapports entre l'État et les pouvoirs locaux en Catalogne (1780-1850) bilan des recherchesm, en DUPUY, R (dir): Pouboir Local et Rétolution, 1780-1850. La frontière intèrieure, Rennes, Pur, pp. 509-518).

- (1995b): «Els lligams politics entre Barcelona i Sarrià al segle XIX: la connexió Vives», en Estudis bistórics i documents dels Arcius de Protocols, XIII, Barcelona, pp. 253-278.

- (1996): «La oposición campo-ciudad en Cataluña durante el trienio liberal. Un estudio de cason, en Trienio, $\pi^{\circ} .28$, pp. 15-50.

- (1997): L'Estaty els poders locals a la Catalunya del segle XIX, Barcelona, Publicacions de l'Abadia de Montserrat, 1997.

TUNÓN DE LARA, M.: Historia y realidad del poder (El poder y las élites en el primer terio de la España del siglo XX), Madrid, Edicusa, 1967.

- Poder y sociedad en España, 1900-1931, Madrid, Espasa, 1992. 